\title{
Importância da Revista Journal of Health Education (IJHE): informação e reflexão sobre ensino na saúde
}

\author{
Importance of the Journal of Health Education: \\ information and reflection on health education
}

\author{
Juarez Antônio Simões Quaresma', Robson José de Souza Domingues' \\ 'Universidade do Estado do Pará, Belém (PA), Brasil.
}

Recebido: Maio 29, 2016 Aceito: Jul. 30, 2016

COMO CITAR ESTE ARTIGO

Quaresma JAS, Domingues RJS Importância da Revista Journal of Health Education (IJHE): informação e reflexão sobre ensino na saúde. Interdisciplinary Journal of Health Education. 2016 Jan-Jul;1(1):1-2 http://dx.doi.org/10.4322/ijhe2016010

\section{CORRESPONDÊNCIA}

Robson José de Souza Domingues Universidade do Estado do Pará

Travessa Perebebuí, 2623, Bairro Marco, CEP 66087-670, Belém (PA), Brasil ijhe@uepa.br

CONFLITO DE INTERESSE

Os autores declararam não

haver conflitos de interesse.

Todos os autores leram e aprovam

a versão final submetida ao

Interdisciplinary Journal of

Health Education (IJHE).
A revista Interdisciplinary Journal of Health Education (IJHE) é um periódico científico de circulação internacional organizado pelo Programa de Pós-Graduação em Ensino em Saúde da Universidade do Estado do Pará. Com a proposta de, inicialmente, ser de periodicidade semestral, conta com a colaboração de revisores nacionais e internacionais com experiência na área de educação em saúde. A revista, cujo escopo vem se somar ao de outras publicações especializadas na área, certamente contribuirá para divulgar os trabalhos do corpo docente ligado ao programa de pós-graduação em Ensino em Saúde, bem como a produção especializada nos espaços acadêmicos regionais, nacionais e até internacionais. A revista contará com a avaliação especializada dos manuscritos submetidos por pares, como a maior parte dos periódicos especializados, e publicará artigos em português e inglês. Vale ressaltar que o aumento da oferta de meios de divulgação científica especializados na área não só potencializa a produção científica especializada, contribuindo para a melhoria da qualidade da pós-graduação na Amazônia, como também divulga aquilo que a academia está produzindo na temática de educação em saúde e seus impactos para a formação de recursos humanos qualificados e melhoria do ensino tanto nas universidades como nos espaços de saúde ligados à formação acadêmica. Finalmente, mais do que ser mais um periódico científico especializado, esta revista é o resultado do trabalho cada vez mais promissor do Programa de Pós-Graduação em Ensino em Saúde da Universidade do Estado do Pará, que tem se tornado referência na área em nosso estado e na Amazônia.

A revista IJHE foi criada com a intenção de ser mais um veículo de informação aos professores, alunos, pesquisadores e profissionais da área da Saúde, a fim de que possam socializar experiências aplicadas ao ensino em espaços formais e não formais, bem como suas produções científicas e saberes acerca do processo de ensino e aprendizagem na área da Saúde. É um periódico interdisciplinar que busca divulgar a resolução de problemas que utilizam várias tecnologias e a interseção do saber de diversas áreas do conhecimento.

Entre os temas, o leitor irá encontrar saberes, relatos de casos e pesquisas acerca do ensino de ética, cidadania e humanização nos vários ambientes da saúde; ensino voltado para atender às necessidades de formação para o sistema de saúde público, o ensino na rede do SUS; ensino em espaços não formais, como hospitais, unidades de saúde, escolas, comunidade e museus, entre outros; práticas pedagógicas para melhorar a educação continuada dos profissionais da saúde. A revista possibilitará o acesso a informações e a estratégias de ensino, tais como Problem-based learning (PBL), Team-based learning (TBL), ensino baseado em simulação, problematização, ensino baseado em projetos, ensino baseado em 


\section{ighe}

competências, mentoring. Divulgará informações sobre tecnologias no ensino: EAD, telessaúde, bases de dados, bibliotecas virtuais, repositórios e produtos educacionais; sobre a importância do processo de ensino-aprendizagem para a formação na graduação, residência médica, multiprofissional e pós-graduação. Irá compartilhar conhecimentos sobre a formação e capacitação docente, mercado de trabalho, gestão, planejamento, avaliação, currículo e cenários de práticas para a interação entre ensino e serviços de saúde.

Portanto, o desafio do presente e a expectativa do futuro são que a revista IJHE ajude os alunos de graduação e pós-graduação, professores, pesquisadores e gestores com informações, reflexões atualizadas e pesquisas de alta qualidade sobre o Ensino em Saúde que possam impactar positivamente a formação dos profissionais da área e, assim, melhorar a qualidade da saúde da população brasileira. 